\title{
O SABER LITERÁRIO E A ESTEREOTIPAÇÃO DO CONHECIMENTO JURÍDICO
}

\author{
JEFERSON DYTZ MARIN ${ }^{1}$
}

\begin{abstract}
RESUMo: A pós-modernidade revela um quadro de crise, representado especialmente no vilipêndio ao caráter distintivodemocrático das instituições e dos indivíduos, que poderia ter na diferença um importante propulsor de políticas inclusivas. Esse processo de encapsulamento do conhecimento e de condensação da literatura ampara a sociedade da informação instantânea, que não constitui conhecimento autêntico. A busca de espaços democráticos que viabilizem uma compreensão dialética do conhecimento passa necessariamente pelo rompimento com esse quadro e pela retomada do caráter intelectivo do direito, a partir de uma reaproximação com a literatura.
\end{abstract}

PALAVRAS-CHAVE: conhecimento jurídico; literatura; estereotipação; democratização.

\section{INTRODUÇÃO}

A lex mercatoria gesta padrões de conduta, linguagem própria e alastra-se em gigahertz, tal como uma peste. Há quem diga que se vive um novo mal do século, bem mais mordaz que a tuberculose de outrora.

Esse encantamento produzido pelas constantes mensagens subliminares fez com que fossem constituídas necessidades prementes, outrora relegadas ao ostracismo e classificadas como inúteis. O senso de coletivo foi-se. Criou-se um sujeito estereotipado que, moldado ao mercado, segue firme o seu papel de consumidor-consumido. E a sedução do

1 Doutor em Direito pela Universidade do Vale do Rio dos Sinos - UNISINOS (Brasil) e Mestre em Direito pela Universidade de Santa Cruz do Sul - UNISC (Brasil). Professor e Coordenador Adjunto do Programa de Mestrado em Direito da Universidade de Caxias do Sul - UCS (Brasil). Bento Gonçalves, RS, Brasil. E-mail: jdmarin@ucs.br 
liberalismo está exatamente no arquétipo de viés psicológico que permite uma oferta irresistível de segurança combinada com liberdade.

Nesse contexto, põem-se o Estado e o próprio direito, vítimas inevitáveis e presas fáceis do Mercado-Leviatã. No direito, os instrumentos de sedução consumerista foram substituídos pela promessa de celeridade consubstanciada nas formas de estandardização da causa. Assim como no mundo hedonista do consumidor-produto, aqui, deixa-se de considerar o critério qualitativo para dar ensejo a um processo massificado de produção em série, assaz distante do caráter intelectivo que a ciência jurídica reclama. Despersonalizam-se as demandas em prol da universalização conceitual que aprisiona a interpretação e amordaça a singularidade do caso.

A morte do consumidor livre, dessa forma, encontra um correspondente no direito: a pena capital da causa e da jurisdição que prima pela fundamentação e pela democratização de uma decisão típica das ciências do espírito, voltada para o critério qualitativo-intelectivo.

$\mathrm{O}$ direito, assim, perde seu caráter literário e enfileira-se à mercantilização da cultura. Cheia de moedeiros falsos, a jurisdição distancia-se da democracia para chancelar a padronização e o perfil único, que pisoteia a diferença includente na pós-modernidade. O julgador deixou de ser produtor para transformar-se em produto. Produto de um sistema que "purifica" o intelecto e o molda à engrenagem produtiva que prima pela quantificação. É preciso produzir! É preciso decidir! É preciso jurisdicionar aos cântaros! Desimporta a peculiaridade do caso ou a personalidade da demanda (e dos jurisdicionados!).

Assim como na literatura, a atividade jurisdicional verte uma simplificação impossível do complexo e busca respostas rápidas, préprontas, sintéticas. De fato, não há como vislumbrar numa decisão que prime por essas características um "ato de convencimento", em cumprimento ao preceito constitucional e mesmo à premissa socrática, há muito dita. O fundamento não é importante, o argumento não conta, o que conta é a quantidade de decisões cuspidas de forma seriática, perfazendo mais uma edição do grande shopping de consumo hedonista que abriga, com seu teto gigante, todo o mundo. 


\section{A CRISE JURÍDICA NA PÓS-MODERNIDADE}

O Estado Moderno enfrenta uma crise de identidade, uma vez que não foi gestada teoria política capaz de fundar a conceituação do perfil alcançado por este Estado que, ora tutela liberdades públicas, ora percebe os direitos sociais enquanto baluartes da cidadania, ora põe-se como mínimo, refém das vicissitudes do mercado.

Nessa esteira, parece indispensável perceber a jurisdição em sua dimensão histórica e ideológica, explicitando seu conteúdo e contextualizando-a diante das crises do Estado Moderno, reconhecendo a necessidade de democratização do ato jurisdicional e de temporalização do direito - religação com o passado - mediante a (re)construção da verdade das teorias da decidibilidade, minimizando-se a interferência do paradigma liberal-mercadológico e valorizando-se a aplicação dos direitos sociais e individuais, com o escopo de firmar políticas inclusivas.

O paradigma liberal-individualista, nessa quadra da história, registra um conflito permanente com o Estado Social, que privilegia a tutela dos direitos difuso-coletivos. Esse embate alcança, também, o Judiciário, que tem registrado uma proximidade conceitual cada vez maior com o poder Executivo, em que pese a clara distinção das atribuições, cunhada desde Montesquieu (2001). Claro que quando se menciona a teoria da tripartição, não se pretende emprestar a ela caráter absoluto, nem tampouco delegarlhe a tarefa de último baluarte do Estado. É notória a demonstração de suas fragilidades ao longo do tempo. Mas a crise do Estado, que tem norteado o debate contemporâneo, ainda não rechaçou a ideia de Montesquieu, por ausência doutra que se revele mais compatível, apesar do Ovídio Baptista da Silva a considerar uma quimera e as decisões judiciais afastarem cada vez mais os traços genéticos da tripartição.

Assim, o rumo da política econômica, cujo nascedouro dá-se no poder executivo, tem encontrado, no Judiciário, reflexos que não poderiam se fazer sentir, já que integram ações típicas do poder executivo, cujo fundamento contempla a proteção dos direitos e garantias fundamentais, tarefa que denota o precípuo mister do Estado-Juiz, sendo vedada a sua afastabilidade programática. 
Claro que não se pretende lançar mão da ideia analítica de que a economia registra nicho de atuação determinado, e, em razão disso, não pode influenciar o Direito, sob pena de estar-se chancelando a aplicação de uma matriz positivista-ortodoxa calcada na teoria pura do direito de Kelsen (1996), que, alinhavada a uma visão cartesiana-linear, não registra pertinência na (pós) modernidade, já que prevalece a concepção que reconhece as diversas áreas científicas como partes do todo e, portanto, potenciais produtores de interferências, que levam a influências mútuas.

A concepção que provém especialmente do constitucionalismo é a de que a ideia de Estado de Direito democraticamente concebido não pode prescindir nem da visão liberal, alicerçada no respeito às diferenças imanentes a uma sociedade plural e heterogênea e tampouco da visão dos comunitaristas, fundada no direito à igualdade, na concepção de organizações sociais que compartilham interesses comuns. Entretanto, a pretensão normativa não tem encontrado receptividade na práxis política, econômica e mesmo jurídica. A verdade é que mesmo os países que registram governos de índole e pretensão socialista - mormente na Europa - acabam por sucumbir ao mercado, priorizando a liberdade e convivendo passivamente com o aumento amazônico da miséria.

Aqui, portanto, não merecem lugar a busca da verdade real, o instrumentalismo processual e a estandardização. Os tribunais não podem partir de um marco zero de sentido e simplesmente "criar" uma (nova) tese, numa concepção darwiniana, como se o ato de julgar constituísse uma experiência de laboratório pensada fisicamente. Fundamental, nesse sentido, firmar a dessemelhança entre eficácia e eficiência, especialmente na esteira do pensamento de Gaiger (2009), Chevallier (2009) e Jania Saldanha (2009). Saldanha relaciona a (pretensa) eficácia ao padrão processual forjado para fazer frente às demandas individuais, sendo a busca da eficiência fruto da concepção universal gestada pelo Banco Mundial, que almeja deitar suas garras em todo o planeta, sempre norteado pelos critérios quantitativos.

A partir do reconhecimento da necessidade de alcance de validade ético-social ao ato jurisdicional e de uma (nova) concepção de eficácia, necessário combater a ideia de recepção dos aspectos econômico-liberais enquanto fundamento de decisão, mediante a consideração incondicional 
dos direitos sociais e fundamentais, tendo como referência o Estado Constitucional.

\section{A INFLUÊNCIA PERNICIOSA DO PANÓPTICO JURÍDICO E A NECESSIDADE DE REDEMOCRATIZAÇÃO DAS DECISÕES}

O panóptico jurídico enclausura o desejo democrático, vilipendia a possibilidade de ruptura paradigmática e, tal como a Medusa, transforma em pedra o direito. E o sentido que aqui se quer emprestar à pedra é de imobilidade, ausência de agir, sentimento de vida estanque imposto por outrem. Quer-se-ia, contudo, que o direito, liberto das correntes opressoras do panóptico, pudesse alcançar o outro sentido de pedra, representado na força, na firmeza, na nitidez de caráter. A pedra que toca o direito, assim, é a que habita o imaginário dos punhos de renda, das anáguas engomadas, que se distancia da farândola popular e acompanha o chá das cinco de um Judiciário inerte, inquisitor e amante da estandardização, impondo conceitos e castrando o saber democrático.

A fala autorizada sufoca a democracia. Os julgadores esquecem os seres iconoclastas e pluricromáticos que habitam a semiologia cortaziana reavivadas por Warat (2000). Transformaram-se em fantasmas pálidos de um cotidiano inóspito, acinzentado e cadavérico. A democracia precisa de jardins, mas jardins multicoloridos. Não pode sobrevier em meio a ervas daninhas e rosas negras.

O Judiciário brasileiro vive as calendas da industrialização decisional, da massificação (des)personalizada dos julgados, olvidando as pessoas que (ainda) insistem em existir e ser a razão dos pleitos que batem às portas do Estado-Juiz. A tecnologia perniciosa motiva os critérios de avaliação quantitativos; e a máquina, que surgiu para servir o homem, agora o submete a seu jugo. Jorge Burgos, o monge cego de Umberto Eco (1996), cujo batismo não se deu por mera coincidência, ambientado na biblioteca, cenário predileto de Jorge Luís Borges - que influenciou decisivamente o escritor italiano -, tremeria diante do infausto.

O direito aproxima-se da literatura de autoajuda e do viés manualesco que inunda as livrarias e salas de aula, passando ao largo do pensar pulsante presente na erudição labiríntica de Borges (2007). Traduz o consumismo hedonista e a incultura que se instalou na sociedade pós- 
moderna. O direito que com pesar se questiona denota um subproduto desse mundo torto e individualista que percebe na autenticidade um desvalor a ser banido.

Aqueles que não compartilham com as estruturas responsáveis pelo triste cenário que se vê precisam da paciência dos ourives. E se é certo que não há um prócer da nação que possa soprar o braseiro e incendiar a verdade que se quer desvelar, também é fato que esses sujeitos (jurisdicionados-produto), hoje tomados por uma espécie de tristeza de sarraceno, com olhos lúgubres e tez negra opaca precisam manter viva a capacidade de indignação, sob pena de chancelar o fim.

O emprego dos instrumentos de estandardização da causa lembra o delírio hermenêutico da Companhia Bananeira da Macondo de Gabriel Garcia Marquez. Em face da afirmação sofista dos causídicos americanos, que atestavam nunca terem existido trabalhadores, confrontando com a sóbria memória dos Buendía, "se dissolveu a patranha do presunto de Virgínia, das pílulas milagrosas e dos reservados natalinos, e se estabeleceu por sentença do tribunal e se proclamou em decretos solenes, a inexistência dos trabalhadores" (Marquez, 1967, p. 182). A estandardização do direito tem essa pretensão. A mesma dos advogados da Companhia de Bananas, a de transformar em existente o plano da inexistência (Marquez, 1967, p. 182).

Apesar de prescindir-se do brilho seráfico e do pergaminho de Melquíades espera-se que a tendência de massificação do direito mude de rumo e a verdade não seja descoberta tarde demais, alcançando-se o mesmo destino que foi reservado aos Buendía da mítica Macondo.

As decisões que registram a pretensão de implantação de um sentido unívoco traduzem imposturas. Carregam consigo o problema genético da falta de autoridade e, embora sejam formalmente chanceladas, não gozam de legitimidade democrática. A democracia não oprime, liberta. A democracia não restringe, inclui. A democracia não tem um discurso monológico, mas plural. A democracia traduz a possibilidade de pleno exercício da vontade fundada na diferença, que a partir da possibilidade da existência multiplica as alternativas e compõe o mosaico de valores que amparam o Estado de Direito. Quando a lanceolada face de animal carnívoro da estandardização será banida pela candura democrática? O 
tempo responderá. É preciso um "dar-se conta" da proximidade do fim. A refundação da democracia jurisdicional. $\mathrm{O}$ resgate da tradição. $\mathrm{O}$ retorno ao elemento humano.

O fundamento das práticas universalizantes, que registram o firme propósito de execução de um projeto de poder jurisdicional calcado na institucionalização de um grupo monolítico, não contribuem em nada para a democratização do Judiciário.

Esse processo de robotização e tentativa vã de (des)burocratizar o Poder Judiciário engessa o humano, rechaça a capacidade de construção intelectiva da decisão e amordaça todo agir transformador. Enquanto o mundo se funda na existência de grupos cada vez mais organizados que traduzem a previsão de evolução da consciência da sociedade civil vertida por Gramsci (2000), o Judiciário apresenta-se indiferente às demandas sociais, mergulhado no mesmo estigma de ode ao contencioso que o caracterizou nos dois últimos séculos.

O homem está desaparecendo para dar lugar a um sujeito-máquina estereotipado e repetidor de uma jurisprudência sintomática cuspida aos cântaros pelos tribunais superiores. Essa espécie de "santo graal" fundamentador que habita a motivação universalizante dos instrumentos de estandardização é, seguramente, fruto do neoliberalismo, que impõe uma gestão terrificante e voltada para o "consumo" de "produtos" habilidosamente cunhados pelo Poder Judiciário.

O processo cunhado pelos tribunais superiores, além de impor o olhar soberbo das decisões inquestionáveis e planificadas, relega as partes, os julgadores e os causídicos à própria sorte, aprisionando a linguagem e enfraquecendo a democracia. É preciso, urgentemente, superar a tentativa de democratização formalista e reconhecer a ingente necessidade de uma democracia material, que resgate o homem em sua plenitude e (re)personalize as demandas.

\section{A IMPORTÂNCIA DO SABER LITERÁRIO NA ERA DA TÉCNICA}

A sensibilidade foi extirpada do ato decisional. A lágrima habita apenas a tez retinta do negro do subúrbio, a face esquálida dos moradores de rua e a anseio não correspondido daqueles que, desprovidos de melhor acesso, padecem com a indiferença da jurisdição. Como assevera o Eduardo 
Galeano, traduzindo sua missão: "Eu escrevo para os que não podem ler. Os debaixo, os que esperam há séculos na fila da história” (2003, p. 16).

O direito distancia-se cada vez mais do sonho acalentado por Galeano, da pedagogia do oprimido de Paulo Freire (2003), da carnavalização de Warat (2000), da superação da cegueira de Saramago (1995), do despertar da alma de Garcia Marquez (1967) e do olhar labiríntico das bibliotecas sem fim de Borges (2007). O direito que a pósmodernidade verteu ainda preserva os ranços romanistas e o alicerce da filosofia da consciência. Com pretensões neoliberais e de cariz contencioso ainda se põe distante de práticas verdadeiramente democráticas, que alcancem os marginalizados e produzam um "direito da rua”: “A opressão, um controle esmagador, é necrófila. Nutre-se do amor à morte e não do amor à vida” (Freire, 2003, p. 45).

Não se quer o direito do senso comum, mas um direito que escute as pessoas e seja desenvolvido nos bairros, considerando a realidade de cada local, de cada comunidade, atentando ao vasto mosaico cultural que compõe o Brasil. Definitivamente, ainda se tem um perfil de Judiciário que, encastelado no gabinete aguarda os litígios solvidos em série. A lembrança das partes, quanto muito, frequenta a vaga memória do julgador, motivada certamente pelos contornos processuais ou de excepcionalidade que o feito possa sugerir.

De fato, a velocidade da comunicação e o avanço da informática, largamente empregados para a construção de esquemas de raciocínio lógico e esquemático têm posto em risco o saber intelectivo, que propõe a alternância de premissas e a inovação do pensar. A organização da sociedade a partir de redes de informatização não tem fomentado apenas a comunicação, mas o constante aprisionamento da inventividade e da capacidade de alterar o curso do conhecimento. O temor é que a organização dessa sociedade pós-moderna se transforme em refém do intérprete-máquina (Freire, 2003). Nesse quadro, “[...] a natureza do saber não permanece intacta. Ele não pode se submeter aos novos canais, e tornar-se operacional, a não ser que o conhecimento possa ser traduzido em quantidades de informação" (Freire, 2003, p. 48).

Nunca o homem cuidou tanto de si a partir da determinação do outro. Nunca a vida autêntica fez tão pouco sentido e a imposição do espécime 
social factóide vingou de forma tão voraz. O atual momento sugere um "modelo horizontal ou em redes, fragmentado e policentrado, no qual os microgrupos identitários se justapõem em um espaço heterogêneo de gostos, de estéticas e de práticas" (Freire, 2003, p. 57)

Mas, como adverte Bauman, "a situação presente emergiu do derretimento radical dos grilhões e das algemas que, certo ou errado, eram suspeitos de limitar a liberdade individual de escolher e de agir" (2001, p. 64). Os estamentos hereditários e a formação societária estanque, que assegurava o status quo e encapsulava as possibilidades de inversão, provocaram a "fluidez" (Bauman, 2001) do tempo, a relativização das estruturas. Os templos do consumismo (Bauman, 2001), que sugerem uma falsa semelhança dos atores, um sentimento de pertencimento, e provocam no homem-consumidor policrônico (Lipovetsky, 2007) a pseudonecessidade de aquisição de bens essenciais, são o retrato do neoliberalismo que, embora ainda comporte sérias discussões como política de Estado, carrega o status de absoluto no mercado consumerista.

E o arquétipo que justifica tal constatação está muito bem erigido em patamares sólidos, firmado em princípios e estatísticas periodicamente renovadas: "Os lugares de compra/consumo oferecem o que nenhuma 'realidade real' externa pode dar: o equilíbrio quase perfeito entre liberdade e segurança” (Lipovetsky, 2007, p. 26). Jónatas Machado expõe a nova limitação imposta à liberdade de expressão, já que a convergência de impulsos competitivos vai estar na base da metáfora do free market place of ideas, dotada de um poder sugestivo e de uma força persuasiva que irão influenciar as liberdades de comunicação (Machado, 2002).

Ao indagar sobre a genealogia do poder, Foucault, a partir do reconhecimento da existência massificada dos instrumentos de dominação e cerceamento das liberdades conscientes, com o claro afã de igualização das pessoas e, também, das instituições, percebe no agir questionador e na dialogia a possibilidade de rompimento do núcleo monológico do poder. A "coerção de um discurso teórico unitário, formal e científico" (Foucault, 2008, p. 44) deve ser combatida através de um processo de reaquecimento dos saberes locais que reúnem características mais profícuas de oposição às práticas universalizantes. 
Essa "discursividade local” (Foucault, 2008) pode, assim, estabelecer uma antítese, um locus de questionamento ao conhecimento científico hierarquizado firmado na genealogia histórica que permeia as estruturas de poder há séculos. Assim, as liberdades plenas, no campo da sexualidade, do poder e das manifestações típicas da personalidade individualizada de cada integrante da comunidade poderão, pari passu, encoleiradas pela pretensão inclusiva, encontrar lugar no nicho fechado do conhecimento estandardizado e hermético: "O silêncio, ou melhor, a prudência com que as teorias unitárias cercam a genealogia dos saberes seria talvez uma razão para continuar. Para multiplicar os fragmentos genealógicos” (Foucault, 2008, p. 56).

O direito, como não poderia deixar de ser, também é fruto dessa avalanche de pensamento voltado para o incremento de um consumo hedonista (Lipovetsky, 2007). O risco é que o jurisdicionado transforme-se num consumidor-produto e que a jurisdição também seja balconizada, retirando o caráter intelectivo que acompanhou a ciência jurídica ao longo da história. E o pior é que esse processo já foi deflagrado. Espera-se que o despertar da consciência da ausência de resolutividade e de seu efeito inverso, já que potencializa os problemas da jurisdição, seja suficiente para o estancamento dessa padronização perniciosa. Mas nem por isso "a ciência perde seus direitos. Na alcova, discutem-se virtudes e vícios; discutem-se fundamentos das religiões, as vias da felicidade, a distinção clássica entre natureza e convenção" (Leford, 1990, p. 33).

Esse homus economicus ou consumidor convertido em mercadoria (Leford, 1990), que denota o retrato dessa época, independentemente da nomenclatura que se queira emprestar, é vítima do tolhimento de alternativas, da ausência de alteridade e pluralidade, da unificação do pensamento científico e da igualização de perfis. E o processo ainda é temperado pelo tempo veloz e pela massificação de procedimentos: "Uma justiça em que a celeridade seja convertida em um metavalor transforma-se em vítima dela própria e aumenta o segundo grau de patologização" (Leford, 1990, p. 35).

Definitivamente, chega-se à "era da técnica” (Heidegger, 2006). As máquinas assumem o lugar do homem e o homem, quando em ação, busca cada vez mais moldar-se às características da máquina, como se esse fosse o 
paradigma concludente do futuro. $\mathrm{O}$ ápice desse estigma concretiza-se no consumismo hedonista que labora no inconsistente coletivo. Pode ser traduzido, por exemplo, na figura do usuário que tomado de cólera externa toda a sua insatisfação com o serviço prestado, recebendo a saudação final da atendente humano-eletrônica sem sobressaltos, em total acinte passivo à manifestação de indignação: Necessita de mais alguma coisa? A companhia [...] agradece e deseja um bom dia.

No século em que a informática avança a passos largos e a velocidade das informações desenvolve-se de forma avassaladora, não se pode, às custas da evolução imanente, tolher dos indivíduos o direito de tutela do Estado e o atendimento humanizado. Essa é uma das típicas atividades que não admitem a substituição do homem pela máquina. Zizek chama atenção ainda para outro risco do mergulho tecnológico desenfreado do mundo contemporâneo: a manipulação biogenética. Amparado em Heidegger, sublinha que o perigo não está nos equívocos das premissas de tal atividade, mas sim no risco de sucesso das manipulações, "nesse ponto, o círculo se fechará e a abertura específica que caracteriza o ser-humano será abolida” (Zizek, 2008, p. 21).

Basta. A humanidade precisa da consciência de seu limite científico. E, embora a "dimensão ontológica seja irredutível à ôntica" (Zizek, 2008, p. 28) e não exista possibilidade de calcular o risco do (aparentemente) impossível, faz-se necessário estabelecer parâmetro para a fixação de uma zona limítrofe do humano. Os meios de estandardização da causa também (des)consideram o elemento humano e põem a própria espécie numa encruzilhada jurisdicional: se o direito foi feito para o homem e é feito pelo homem, poderá ele tornar-se um ciberdireito, um subproduto da máquina? Espera-se que a ordem aparente das coisas seja invertida e o prenúncio do fim do humano no jurídico não se concretize.

\section{CONSIDERAÇÕES FINAIS}

Premido e calcificado pela azáfama dos dias, sufocado por um cotidiano próximo mas paradoxalmente inóspito, o homem esquece de si mesmo e rechaça qualquer sopro de valorização da singularidade. Pouco a pouco acaba sendo engolido pela igualização ditada por uma crescente estandardização patrocinada pelos meios de comunicação, pelos meios de 
produção que se alicerçam cada vez mais na massificação e, também, pelo direito, encapsulado numa espécie de subsunção pós-moderna, que veste o positivismo doutra roupagem, mas registra um efeito ainda mais nefasto. Os espelhos indicam como o homem gostaria de viver, mas não vive. As veias ainda sangram....

Os fantasmas pálidos do cotidiano não resistem ao processo de estereotipação que deita suas garras vorazes, mais intensas a cada dia que passa. Parecem zumbis narcisistas e de forma inconsciente idolatram a aparência, olvidando as relações em rede e a concepção de indivíduo coletivo, ínsita ao agir democrático. A era cibernética, como sentenciou Lafontaine, deixa sua herança mais perniciosa: a do assassínio do conhecimento intelectualizado e crítico. A informação torna-se cada vez mais breve, sintetizada e direta. O pensar dá lugar à assimilação limitada, que verte um mero introjetar e distancia-se do compreender. As relações expandidas pela comunicação eletrônica acabam por gerar uma informação futilizada, rasa e voltada para uma produção anti-intelectual. A rede, espaço com grande potencial para o exercício democrático, tornou-se o locus da repetição idiotizada de um frenesi apoteótico norteado pela igualização de perfis.

O modelo teórico da cibernética, firmado no princípio neguentrópico, reduziu o humano a um código genético. Está inagurada a era em que o homem, comparado com a máquina, é codificado, reduzindo-se os seres vivos a uma situação informacional que (des)considera a cor da pele, a semiótica, a expressão da tez ou a capacidade inventiva. Não há lugar para construção do conhecimento, mas apenas para o balbuciar de uma ideia vã, de palavras inúteis que se repetem de forma estéril, fruto de um processo de tecnificação desenvolvido à revelia do elemento humano.

$\mathrm{O}$ quadro que se apresenta, fruto da autoridade persuasiva e subliminar imposta pelo mercado e pelas instituições, estereotipadas por essa vontade invisível, firma-se no intérprete-máquina e no paradoxo do homem sem o elemento humano. O afã de tecnificação do conhecimento e de condensação da literatura (se é que o termo se aplica a tais produções) molda boa parte dos (re)produtores da informação. E cá se diga que informação distingue-se de conhecimento, na medida em que a primeira, ao 
menos na pós-modernidade, apresenta-se de forma acrítica e blindada, sepultando os espaços democráticos da dialética.

Testemunhar essa prova de que o mundo, embora pareça cinza, ainda registra aquarelas que lhe podem colorir, que lhe podem dar vida, que lhe podem manter desperto, traduz uma necessidade.

É necessário romper com esse mundo paralelo antiliterário, apocalíptico. Com a terra do sem fim. O retrato do caminho sem partida. Precisa-se de incerteza. Precisa-se de desordem. Precisa-se de inconstância...

\section{REFERÊNCIAS}

AGAMBEN, G. Estado de exceção. Trad. de Iraci D. Poleti. São Paulo: Boitempo, 2007.

ARISTÓTELES. Rhétorique. Trad. de Médéric Dufour. Paris: Societé D’Édition, 1932. (coll. "Les Belles Lettres").

BAUMAN, Z. Modernidade líquida. Rio de Janeiro: J. Zahar, 2001.

BOBBIO, N. A era dos direitos. Rio de Janeiro: Campus, 2004.

BORGES, J. L. Ficções. São Paulo: Comp. das Letras, 2007.

CHEVALIER, J. O estado pós-moderno. Belo Horizonte: Fórum, 2009.

DESCARTES, R. Discurso do método. Trad. de João Cruz Costa. Rio de Janeiro: J. Olympio, 1960.

ECO, U. O nome da rosa. Trad. de Aurora Fornoni Bernardini e Homero Freitas de Andrade. Rio de Janeiro: Nova Fronteira, 1986.

FOUCAULT, M. A ordem do discurso: aula inaugural no Còllege de France, pronunciada em 2 de dezembro de 1970.Trad. de Laura Fraga de Almeida Sampaio. São Paulo: Loyola, 2003.

FOUCAULT, M. Microfísica do poder. São Paulo: Graal, 2008.

FREIRE, P. Pedagogia do oprimido. 37. ed. São Paulo: Paz e Terra, 2003.

GAIGER, L. I. Eficiência. In: CATTANI, Antonio David et al. Dicionário internacional de outra economia. Coimbra: Almedina, 2009. p. 36-59.

GALEANO, E. O livro dos abraços. Trad. de Eric Nepomuceno. Porto Alegre: L\&PM, 2003.

GRAMSCI, A. Cadernos do cárcere. São Paulo: Civilização Brasileira, 2000.

HALL, S. A identidade cultural na pós-modernidade. Trad. de Tomaz Tadeu da Silva e Guacira Lopes Louro. 7. ed. Rio de Janeiro: D\&P, 2002.

HEIDEGGER, M. Caminhos de floresta. Trad. de Irene Borges Durante Filipa Pedroso. Lisboa: Calouste Gulbenkian, 1998.

HEIDEGGER, M. Ser e tempo. Petrópolis: Vozes, 2006. 
KELSEN, H. Teoria pura do direito. Trad. de João Baptista Machado. São Paulo: Martins Fontes, 1996.

LEFORD, C.S. O desejo de saber e o desejo de corromper. In: NOVAES, Adauto (Org.). O desejo. São Paulo: Comp. das Letras, 1990. p.34-56.

LIPOVETSKY, G. A felicidade paradoxal: ensaio sobre a sociedade de hiperconsumo. Trad. de Maria Lúcia Machado, São Paulo: Comp. das Letras, 2007.

LYOTARD, J. F. A condição pós-moderna. Rio de Janeiro: J. Olympio, 2000.

MACHADO, J. E. M. Liberdade de expressão: dimensões constitucionais da esfera pública no sistema social. Coimbra: Coimbra, 2002.

MARQUEZ, G. G. Cem anos de solidão. Trad. de Eliane Zagury, Rio de Janeiro: Record, 1987.

MONTESQUIEU. O espírito das leis. Trad. de Luiz Fernando de Abreu Rodrigues. Curitiba: Juruá, 2001.

MOZOS, J.L. Derecho civil: metodo, sistemas y categorias jurídicas. Madrid: Civitas, 1998.

PLATÃO. Crátilo: diálogo sobre a justeza dos nomes. Trad. de Pe. Dias Palmeira. 2. ed. Lisboa: Sá da Costa Editora, 1994.

ROSS, A. Sobre el derecho y la justicia. Trad. de Genaro R. Carrió. 5. ed. Buenos Aires: EUDEBA, 1994.

SALDANHA, J. M. L. A influência do neoliberalismo na jurisdição: a difícil sintonia entre eficiência e efetividade. In: MARIN, Jeferson Dytz (Coord.). Jurisdição e processo: estudos em homenagem ao Prof. Ovídio Baptista da Silva, vol. III. Curitiba: Juruá, 2009.p. 44-63.

SALDANHA, J. M. L. Do funcionalismo processual da aurora das luzes às mudanças processuais estruturais e metodológicas do crepúsculo das luzes: a revolução paradigmática do sistema processual e procedimental de controle concentrado da constitucionalidade do STF. In: CALLEGARI, André Luís; STRECK, Lenio Luiz; ROCHA, Leonel Severo (Org.). Constituição, sistemas sociais e hermenêutica: Anuário do Programa de Pós-Graduação em Direito da Unisinos, n. 8. Porto Alegre: Livraria do Advogado, 2009. p. 33-48.

SALDANHA, J. M. L. Tempos de processo pós-moderno: o dilema cruzado entre ser hipermoderno e antimoderno. In: THEODORO JÚNIOR, Humberto; CALMON, Petrônio; NUNES, Dierle. Processo e constituição: os dilemas do processo constitucional e dos princípios processuais constitucionais. Rio de Janeiro: GZ, 2010. p. 88- 106.

SARAMAGO, J. Ensaio sobre a cegueira. São Paulo: Comp. das Letras, 1995 .

SILVA, O. Baptista da. Processo e ideologia: o paradigma racionalista. 2. ed. Rio de Janeiro: Forense, 2004.

STRECK, L. L. Verdade e consenso. Rio de Janeiro: Lumen Juris, 2006. 
WARAT, L. A. A ciência jurídica e seus dois maridos. Santa Cruz do Sul: EDUNISC, 2000.

WARAT, L. A. Epistemologia e ensino do direito: o sonho não acabou. Florianópolis: Fundação Boiteux, 2004.

WELZEL, H. Introducción a la filosofía del derecho: derecho natural y justicia material. Traducción de Felipe González Vicen. 2. ed. Madrid: Aguilar, 1979.

WIEACKER, F. História do direito privado moderno. Trad. de A. M. Botelho Hespanha. 2. ed. Lisboa: Calouste Gulbenkian, 1967.

ZIZEK, S.A visão em paralaxe. Trad. de Maria Beatriz Medina, São Paulo: Boitempo, 2008.

Idioma original: Português

Recebido: 12/07/15

Aceito: 10/01/16 